\title{
Ginger extract diminishes chronic fructose consumption-induced kidney injury through suppression of renal overexpression of proinflammatory cytokines in rats
}

Ming Yang ${ }^{1}$, Changjin Liư ${ }^{2}$ Jian Jiang ${ }^{3}$, Guowei Zuo ${ }^{2}$, Xuemei Lin ${ }^{1}$, Johji Yamahara ${ }^{4}$, Jianwei Wang ${ }^{5^{*}}$ and Yuhao $\mathrm{Li}^{3^{*}}$

\begin{abstract}
Background: The metabolic syndrome is associated with an increased risk of development and progression of chronic kidney disease. Renal inflammation is well known to play an important role in the initiation and progression of tubulointerstitial injury of the kidneys. Ginger, one of the most commonly used spices and medicinal plants, has been demonstrated to improve diet-induced metabolic abnormalities. However, the efficacy of ginger on the metabolic syndrome-associated kidney injury remains unknown. This study aimed to investigate the impact of ginger on fructose consumption-induced adverse effects in the kidneys.

Methods: The fructose control rats were treated with 10\% fructose in drinking water over 5 weeks. The fructose consumption in ginger-treated rats was adjusted to match that of fructose control group. The ethanolic extract of ginger was co-administered (once daily by oral gavage). The indexes of lipid and glucose homeostasis were determined enzymatically, by ELISA and/or histologically. Gene expression was analyzed by Real-Time PCR.

Results: In addition to improve hyperinsulinemia and hypertriglyceridemia, supplement with ginger extract (50 mg/kg) attenuated liquid fructose-induced kidney injury as characterized by focal cast formation, slough and dilation of tubular epithelial cells in the cortex of the kidneys in rats. Furthermore, ginger also diminished excessive renal interstitial collagen deposit. By Real-Time PCR, renal gene expression profiles revealed that ginger suppressed fructose-stimulated monocyte chemoattractant protein-1 and its receptor chemokine (C-C motif) receptor-2. In accord, overexpression of two important macrophage accumulation markers CD68 and F4/80 was downregulated. Moreover, overexpressed tumor necrosis factor-alpha, interleukin-6, transforming growth factor-beta1 and plasminogen activator inhibitor (PAl)-1 were downregulated. Ginger treatment also restored the downregulated ratio of urokinase-type plasminogen activator to PAI-1.

Conclusions: The present results suggest that ginger supplement diminishes fructose-induced kidney injury through suppression of renal overexpression of macrophage-associated proinflammatory cytokines in rats. Our findings provide evidence supporting the protective effect of ginger on the metabolic syndrome-associated kidney injury.
\end{abstract}

Keywords: Zingiber officinale Roscoe, Renoprotection, Anti-inflammation, Metabolic abnormalities

\footnotetext{
*Correspondence: wangjianwei1968@gmail.com; yuhao@sitcm.edu.au

${ }^{5}$ Department of Traditional Chinese Medicine, Chongqing Medical University, Chongqing 400016, China

${ }^{3}$ Endocrinology and Metabolism Group, Sydney Institute of Health Sciences/

Sydney Institute of Traditional Chinese Medicine, Sydney, NSW 2000,

Australia

Full list of author information is available at the end of the article
}

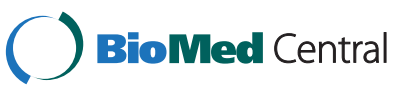

(c) 2014 Yang et al.; licensee BioMed Central Ltd. This is an Open Access article distributed under the terms of the Creative Commons Attribution License (http://creativecommons.org/licenses/by/2.0), which permits unrestricted use, distribution, and reproduction in any medium, provided the original work is properly credited. The Creative Commons Public Domain Dedication waiver (http://creativecommons.org/publicdomain/zero/1.0/) applies to the data made available in this article, unless otherwise stated. 


\section{Background}

The metabolic syndrome is a well-established risk factor for diabetes, cardiovascular disease and mortality. Recently, studies have suggested that the metabolic syndrome may also contribute to the development of chronic kidney disease. Data from the Third National Health and Nutrition Examination Survey has shown an independent association between the metabolic syndrome and chronic kidney disease [1]. This connection has been further corroborated by the finding that the metabolic syndrome increases the risk of developing new-onset chronic kidney disease [2]. Indeed, renal injury is often seen in various animal models of the metabolic syndrome, such as Zucker diabetic fatty rats $[3,4]$ and $d b / d b$ mice [5].

The Western-style diet, characterized by an overavailability of food, with high intakes of high-fat foods, highsugar desserts and drinks, as well as high intakes of red meat, refined grains, and high-fat dairy products, affects multiple metabolic functions and has been associated with a higher incidence of the metabolic syndrome. It has been suggested that the Western-style diet is a major risk factor for impaired kidney function and chronic kidney disease [6]. Notably, fructose has now become a major constituent of our modern diet. Fructose consumption has steadily increased over the past 30 years in parallel to the growth of the obesity/metabolic syndrome epidemic, and fructose and high-fructose corn syrup are ingredients in many commercially produced food products [1]. It has been hypothesized that fructose consumption in our diet may be among the factors that contribute to the epidemic of the metabolic syndrome and, consequently, to the epidemic of chronic renal disease [1,7-11]. This hypothesis is supported by the preliminary evidence demonstrating that high fructose consumption induces kidney damages in both rats [12-14] and mice [15].

Ginger (Zingiber officinale Roscoe, Zingiberacae) is one of the most commonly used spices and medicinal plants around the world. It has been demonstrated that ginger has pleiotropic pharmacological activities, such as gastrointestinal, analgesic, anti-inflammatory, antioxidant and cardiovascular activities $[16,17]$. The renoprotective effects of ginger have also been reported in the animal models of ischemia/reperfusion- [18,19], alcohol- [20,21], streptozotocin- [22] and carbon tetrachloride- [23] induced renal injuries. However, the efficacy of ginger on the metabolic syndrome-associated kidney damages remains unknown. We have recently demonstrated that ginger supplement improves fructose consumption-induced fatty liver [24] and adipose tissue insulin resistance [25] in rats. In the present study, we examined the impact of ginger on chronic fructose consumption-induced kidney injury in rats. Furthermore, the underlying mechanisms were also investigated.

\section{Methods}

Preparation and identification of the ethanolic extract of ginger

Ginger rhizomes were collected from the suburban area of Hanoi, Vietnam, and identified botanically by Professor Johji Yamahara, who is an expert in taxonomy. A voucher specimen was deposited in Pharmafood Institute, Kyoto, Japan (Voucher specimen No: PS0088). The extract used in the present study was prepared using an ethanolic method described previously [24]. Briefly, $5 \mathrm{~kg}$ of sliced dry ginger rhizomes including the skins were immersed in $5 \mathrm{~L}$ of $95 \%$ ethanol with intermittent shaking for $24 \mathrm{~h}$, and then refluxed for $3 \mathrm{~h}$ by heating. The filtrate was evaporated below $45^{\circ} \mathrm{C}$ under reduced pressure. The residue (yield: 9.6\%) was designated as an alcoholic extract. The extract was quantified by a HPLC method described previously [26] to contain two representative components: 6-gingerol and 6-shogaol at 4.4\% and 1.1\%, respectively.

\section{Animals, diet and experimental protocol}

All animal procedures were in accordance with the 'Principles of laboratory animal care' (http://grants1.nih. gov/grants/olaw/references/phspol.htm) and were approved by the Animal Ethics Committee of Chongqing Medical University, China.

Male Sprague-Dawley rats aged 7-9 weeks (210-230 g) and standard laboratory chow were supplied by the Laboratory Animal Center, Chongqing Medical University, China. Rats were housed in a temperature controlled facility (21 \pm $1^{\circ} \mathrm{C}, 55 \pm 5 \%$ relative humidity) with a 12 -h light/dark cycle. Animals were allowed free access to water and standard chow for at least 1 week prior to starting the experiments.

Research has shown that sugar-sweetened nonalcoholic beverages, such as soft drinks, appear as the major source of fructose for all classes of age considered, except for children younger than 6 years and adults older than 50 years [27]. Therefore, fructose in drinking water was used in the present study, in accordance to this rationale and the previous research protocol $[24,25,28,29]$.

Dosage selection is of exceptional importance for pharmacological intervention. Excessively high dosages in animals may result in non-specific ("artificial") effects, which may be dissociated with those in humans. A 35-day toxicity study in rats has demonstrated that the dried ginger powder at the dosages of 500, 1000 and $2000 \mathrm{mg} / \mathrm{kg}$ (equivalent to $48-192 \mathrm{mg} / \mathrm{kg}$ ethanolic extract used in the present study) was not associated with any mortalities and abnormalities in general conditions, behavior, growth, food and water consumption, hematological and blood biochemical parameters [26]. Previous studies have reported that treatment with dried ginger powder at a dosage of 200 [30] or 500 [31] mg/ $\mathrm{kg}$ (equivalent to 19.2 or $48 \mathrm{mg} / \mathrm{kg}$ ethanolic extract used in the present study) alleviated streptozotocin-induced the metabolic syndrome-associated or renal dysfunctions in rats. 
Table 1 Primer sequences for Real Time PCR assays

\begin{tabular}{lll}
\hline Gene & Forward primers & Reverse primers \\
\hline$\beta$-actin & ACGGTCAGGTCATCACTATCG & GGCATAGAGGTCTTACGGATG \\
MCP-1 & CGGTTCTCCCTTCTACTTCCTG & GCTCTGCCTCAGCCTTTATTG \\
CCR-2 & GAAGACCCAAAGACCAAGATGC & TCTGACAACAAAGCAGGAGGTG \\
CD68 & ACTGGGGCTCTTGGAACTACAC & CCTTGGTTTGTTCGGGTTCA \\
F4/80 & ATCGCTGCTGGCTGAATACG & GCAACCTCGTATCCTTGAGCTTAG \\
TNF-a & ATGGGCTCCCTCTCATCAGTTC & CTCCTCCGCTTGGTGGTTG \\
IL-6 & GTTGCCTTCTTGGGACTGATGT & GGTCTGTTGTGGGTGTATCCT \\
TGF- $\beta$ & GATCAGTCCCAAACGTCGAGG & CAGGTGTGAGCCCTTTCCAG \\
PAI-1 & GAACGCCCTCTATTTCAACGG & AGTTCCAGGATGTCGTACTCGTG \\
UPA & GCTTCGGACAAGAGAGTGCCA & GCCATAGTAGTGAGGCTGCTTGC \\
\hline
\end{tabular}

Sequences: $5^{\prime}$ to $3^{\prime}$.

In humans, 3-9 g dried ginger (equivalent to 288$864 \mathrm{mg}$ ethanolic extract used in the present study) is the officially accepted dosages (Version 1, 2010 Chinese Pharmacopoeia). Based on the above information, the dosages of 20 and $50 \mathrm{mg} / \mathrm{kg}$ ethanolic extract were selected for the present study.

Twenty-four rats were divided into 4 groups $(n=6$ per group): (1) water control, free access to water; (2) fructose control, free access to $10 \%$ fructose solution $(\mathrm{w} / \mathrm{v}$, preparation every day); (3) fructose + ginger $20 \mathrm{mg} / \mathrm{kg}$ and (4) fructose + ginger $50 \mathrm{mg} / \mathrm{kg}$. There was no difference in body weight between the groups before treatments commenced. Animals in ginger-treated groups were administered ginger extract at 20 and $50 \mathrm{mg} / \mathrm{kg}$ (suspended in 5\% Gum Arabic solution, gavage once daily) for 5 weeks, respectively. The rats in the corresponding water- and fructose-control groups received vehicle (5\% Gum Arabic) alone. All rats had free access to the standard chow. To avoid stress and maintain accurate monitoring of fructose intake, only 2 rats were housed in a cage at any given time. The consumed chow and fructose solution were measured per 2 rats daily and the intake of fructose was calculated. Initial experiments showed that when compared to the vehicle alone, ginger treatment significantly increased the intake of the $10 \%$ fructose water when the rats were given free access. In order to exclude the influence resulting from differences in fructose intake, fructose consumption in the groups treated with the ginger extracts were adjusted by regulating the concentration of fructose solution daily to match that of the fructose control group on the previous day.

At the end of week 4, the rats were fasted overnight before blood samples were collected by retroorbital venous puncture under ether anesthesia at 9:00-12:00 am for determination of plasma concentrations of total cholesterol (kit from Kexin Institute of Biotechnology, Shanghai, China), triglyceride (Triglyceride-E kit, Wako, Osaka, Japan), glucose (kit from Kexin Institute of Biotechnology, Shanghai, China) and insulin (kit from Morinaga Biochemical Industries, Tokyo, Japan). At the end of week 5 , the rats were weighed and killed by prompt dislocation of the neck vertebra. Kidneys and epididymal fat tissues

Table 2 General parameters $(n=6)$

\begin{tabular}{|c|c|c|c|c|}
\hline & \multirow{2}{*}{$\begin{array}{c}\text { Water } \\
\text { Ginger } 0\end{array}$} & \multicolumn{3}{|c|}{ Fructose } \\
\hline & & Ginger 0 & Ginger 20 & Ginger 50 \\
\hline Fructose intake $(\mathrm{g} / 2$ rats $/ 5 \mathrm{w})$ & - & $845 \pm 33$ & $827 \pm 13$ & $832 \pm 18$ \\
\hline Chow intake (g/2 rats/5 w) & $1993 \pm 100^{*}$ & $1083 \pm 74$ & $1156 \pm 29$ & $1156 \pm 52$ \\
\hline Body weight (g) & $333 \pm 7$ & $338 \pm 11$ & $324 \pm 7$ & $318 \pm 6$ \\
\hline Epididymal fat weight (g) & $4.14 \pm 0.46$ & $4.81 \pm 1.10$ & $4.49 \pm 0.46$ & $3.93 \pm 0.25$ \\
\hline Plasma glucose (mmol/L) & $4.74 \pm 0.11$ & $4.92 \pm 0.23$ & $4.87 \pm 0.25$ & $4.02 \pm 0.18^{*}$ \\
\hline Plasma insulin (pmol/L) & $8.57 \pm 1.10^{*}$ & $16.26 \pm 2.86$ & $15.60 \pm 0.88$ & $7.91 \pm 0.44^{*}$ \\
\hline Plasma TG (mmol/L) & $0.47 \pm 0.03^{*}$ & $1.01 \pm 0.09$ & $0.96 \pm 0.08$ & $0.45 \pm 0.07^{*}$ \\
\hline Plasma TC (mmol/L) & $1.83 \pm 0.06^{*}$ & $2.57 \pm 0.12$ & $2.60 \pm 0.08$ & $2.75 \pm 0.14$ \\
\hline Plasma BUN (mmol/L) & $6.78 \pm 0.64$ & $7.10 \pm 1.04$ & $7.71 \pm 0.86$ & $7.85 \pm 0.57$ \\
\hline Plasma creatinine $(\mu \mathrm{mol} / \mathrm{L})$ & $45.81 \pm 6.12$ & $51.92 \pm 9.23$ & $44.21 \pm 7.62$ & $45.03 \pm 4.64$ \\
\hline
\end{tabular}

$\mathrm{TG}$, triglyceride; $\mathrm{TC}$, total cholesterol; vs fructose control (ginger 0 ), ${ }^{*} P<0.05$. 
were collected and weighed. The ratio of kidney weight to body weight was calculated. Segments of kidney were flash frozen in liquid nitrogen and stored at $-80^{\circ} \mathrm{C}$ for subsequent determination of lipid contents and gene expression.

\section{Histological examination of kidney}

All slides were examined by two different researchers in a blinded manner. Morphometric quantification was assessed by microscopy (IX-81, Olympus Corporation, Tokyo, Japan) using a NIH ImageJ (version 1.43) analyzing system.

A portion of kidney was fixed with $10 \%$ formalin and embedded in paraffin. Three-micron thick sections were cut and stained with hematoxylin and eosin. The sections were imaged and cross-sectional areas were estimated in glomeruli that were cut transversely. The outer borders of the glomeruli were traced at $200 \times$ magnification, and glomerular tuft area was measured. Fifty glomeruli per kidney were counted, and the mean values of these estimates were used in analyses. To further investigate the damage, an additional section (two-micron thickness) fixed in a 4\% paraformaldehyde solution was stained with periodic acid-Schiff (PAS) and examined as previously described [13] using light microscopy and blinded assessors. Tubular size was determined by outlining each tubular profile. 200 tubules in each kidney section were examined.
Tubular injury (by counting the number of tubules that exhibited cast formation, slough and dilation of tubular epithelial cells) was evaluated.

To determine the degree of collagen fiber accumulation, a kidney section (two-micron thickness) was stained with Masson's trichrome. Forty fields in different sections were randomly selected, and Masson's trichrome-stained area (blue) and total tissue area were determined. Their ratio was calculated as interstitial collagen deposit (fibrosis).

To observe lipid accumulation, six-micron frozen kidney sections were stained with Oil Red O.

\section{Determination of triglyceride and total cholesterol contents in kidney}

Triglyceride and total cholesterol contents in kidney were determined as described previously [24,28]. Briefly, $100 \mathrm{mg}$ of tissue was homogenized and extracted with $2 \mathrm{ml}$ of isopropanol. After centrifugation $\left(1000 \times \mathrm{g}, 10 \mathrm{~min}\right.$ at $\left.4^{\circ} \mathrm{C}\right)$, the triglyceride and total cholesterol contents in supernatants were determined enzymatically (Wako, Osaka, Japan).

\section{Real-time PCR}

Total RNA was isolated from kidneys of individual rats using TRIzol (Takara, Dalian, China). cDNA was synthesized using M-MLV RTase cDNA Synthesis Kit (Takara, Dalian, China) according to the manufacturer's

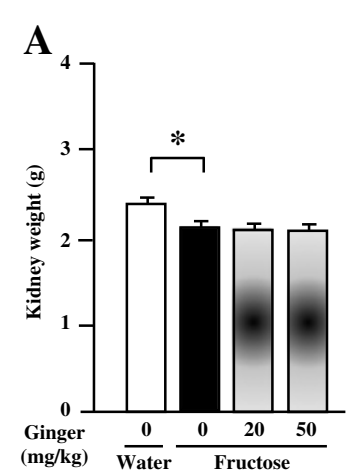

D

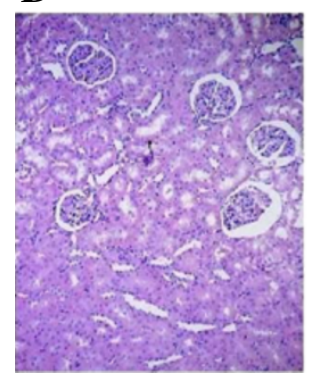

Water control

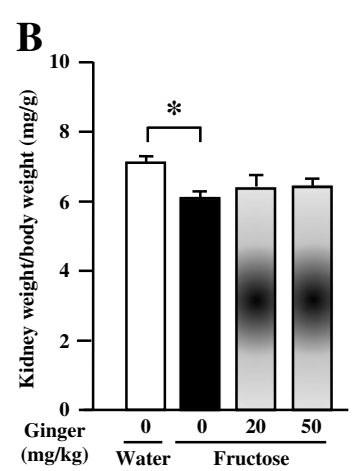

F

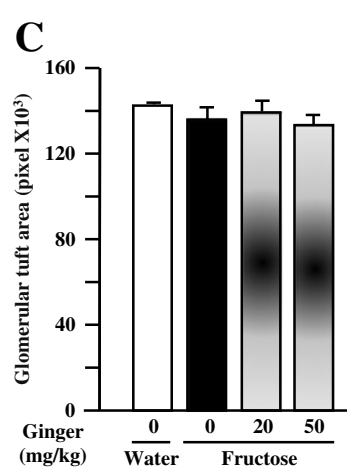

G

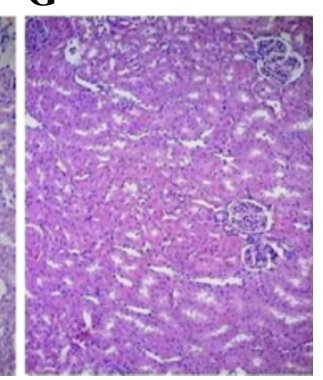

Figure 1 Kidney weight (A), the ratios of kidney weight to body weight (B), glomerular tuft area (C) and representative images showing renal histology (hematoxylin and eosin, magnification: 100X, D-G) in rats. The fructose control rats had free access to $10 \%$ fructose in their drinking water over 5 weeks, while the consumption of fructose in the ginger (20 or 50 mg/kg)-treated (by gavage daily) rats was adjusted to that of the fructose control rats. The water-control rats had free access to tap water. All values are means $\pm S E M\left(n=6\right.$ each group). ${ }^{*} P<0.05$. 
instructions. Real-Time PCR was performed with the CFX 96 Real Time PCR Detection System (Biorad Laboratories Inc, Hercules, CA, USA) using the $\mathrm{SYBR}^{\circ}$ Premix Ex Taq ${ }^{\text {Ti }}$ II (Takara, Dalian, China). The sequences of primers are shown in Table 1. The gene expression from each sample was analysed in duplicates and normalized against the internal control gene $\beta$-actin. Levels in water control rats were arbitrarily assigned a value of 1 .

\section{Data analysis}

All results are expressed as means \pm SEM. Data were analyzed by ANOVA using the StatView software (Version 5.0.1, SAS Institute Inc. USA), and followed by The Student-Newman-Keuls test to locate the differences between groups. $P<0.05$ was considered to be statistically significant.

\section{Results}

General characteristics of the effects of ginger extract in fructose-fed rats

Compared to water drinking, intake of $10 \%$ fructose solution decreased intake of chow (Table 2). After 4-week supplementing with fructose, plasma concentrations of insulin, total cholesterol and triglyceride were elevated, whereas glucose concentration remained unchanged (Table 2). Rats in the fructose control and fructose ginger $(20$ and $50 \mathrm{mg} / \mathrm{kg}$ ) groups showed similar intakes of fructose and chow. However, supplementing with a ginger extract at $50 \mathrm{mg} / \mathrm{kg}$ significantly decreased plasma concentrations of glucose, insulin and triglyceride, but it did not affect plasma total cholesterol concentration in fructose-fed rats (Table 2). Ginger extract at $20 \mathrm{mg} /$ $\mathrm{kg}$ showed minimal effect across all parameters shown in Table 2.

\section{Effects on kidney-related variables in rats}

Fructose feeding did not significantly affect plasma BUN and creatinine (Table 2), body weight (Table 2) and glomerular tuft area (Figure 1C, D-G) in rats. However, it decreased kidney weight (Figure 1A) and the ratio of kidney weight to body weight (Figure 1B). Supplementing with a ginger extract at 20 and $50 \mathrm{mg} / \mathrm{kg}$ did not significantly affect these parameters in fructose-fed rats (Table 2, Figures 1A-G).

Importantly, fructose induced a pronounced increase in tubular damage in both the cortex and outer stripe of the medullas characterized by the focal cast formation, slough and dilation of tubular epithelial cells (Figures 2A, B, 3A
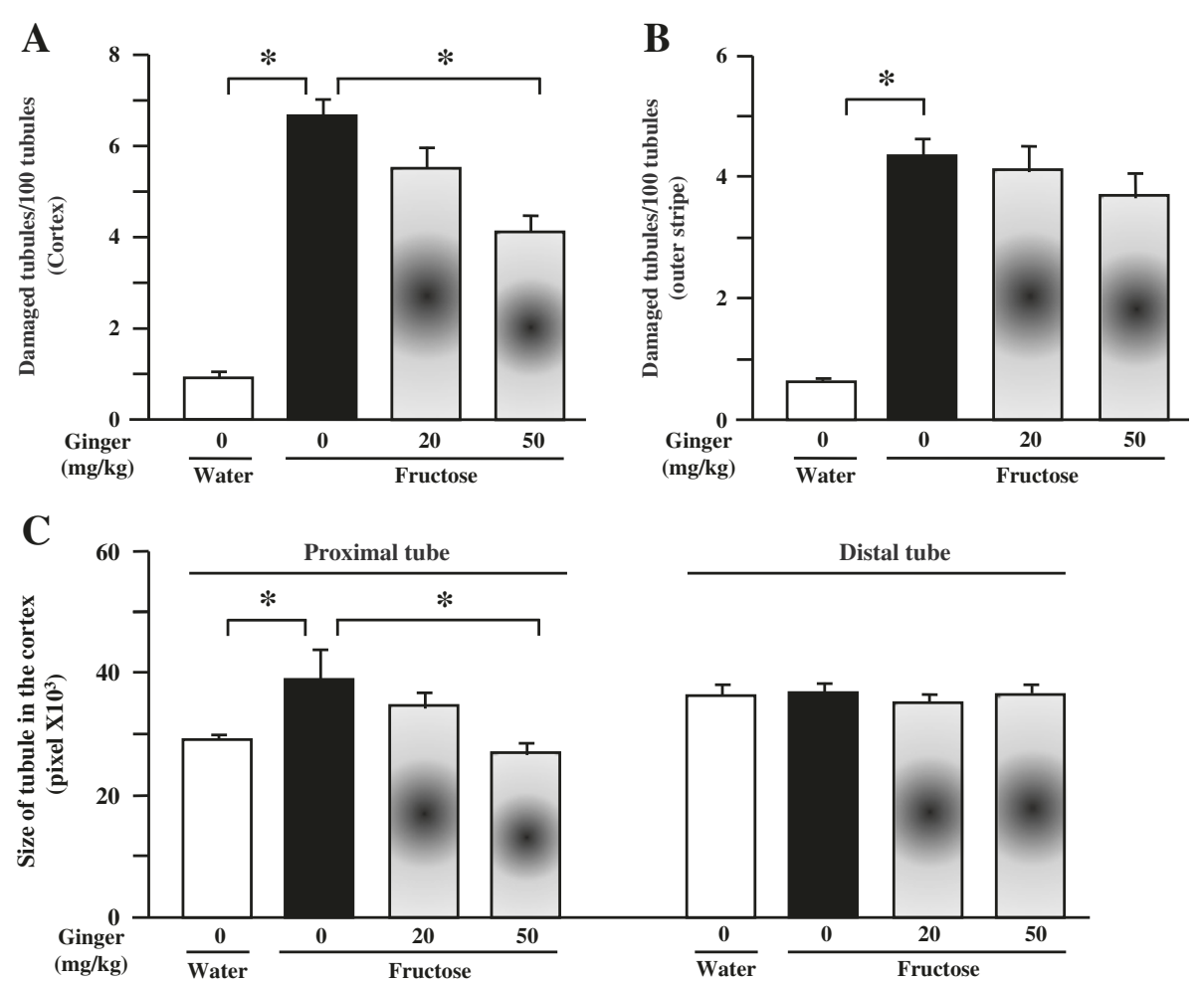

Figure 2 Damaged tubules characterized by focal cast formation, slough and dilation of tubular epithelial cells in the cortex (A) and outer of stripe (B), and size of proximal and distal tubes in the cortex (C) of kidney in rats. The fructose control rats had free access to $10 \%$ fructose in their drinking water over 5 weeks, while the consumption of fructose in the ginger (20 or $50 \mathrm{mg} / \mathrm{kg}$ )-treated (by gavage daily) rats was adjusted to that of the fructose control rats. The water-control rats had free access to tap water. All values are means \pm SEM $(n=6$ each group). ${ }^{*} P<0.05$. 
and B). Further analysis showed that fructose feeding increased the size of proximal, but not distal tubules in the cortex (Figure 2C, Figures 3A-H). Treatment with ginger extract at $50 \mathrm{mg} / \mathrm{kg}$ significantly decreased the damage of tubules in the cortex, but not in the outer stripe of the medullas (Figures 2A and B). Furthermore, this supplement decreased the enlargement of proximal tubules, whereas the size of distal tubules in the cortex was not affected (Figure 2C, Figures 3A-H). Ginger extract at $20 \mathrm{mg} / \mathrm{kg}$ failed to significantly affect these variables (Figures $2 \mathrm{~A}-\mathrm{C}$, Figures $3 \mathrm{~B}$ and $\mathrm{C}$, and Figures $3 \mathrm{~F}$ and $\mathrm{G}$ ).

In addition, fructose feeding increased the ratio of the Masson's trichrome-stained area to total tissue area in the renal interstitium (Figures 4A-C). Supplementing with a ginger extract at $50 \mathrm{mg} / \mathrm{kg}$ significantly inhibited this increase (Figures $4 \mathrm{~A}, \mathrm{C}$ and $\mathrm{E}$ ), whereas the lower dosage of ginger extract showed minimal effect (Figures 4A, C and D).
In contrast to the tubular injury and interstitial fibrosis, renal triglyceride (Figure 5A) and total cholesterol (Figure 5B) contents were not altered by fructose feeding. Unchanged lipid accumulation was further confirmed by Oil Red O staining (Figures 5C and D). Treatment with a ginger extract at either low or high dosage did not affect renal lipid contents in fructose-fed rats (Figures 5A, B, E and F).

\section{Renal gene expression profiles in rats}

As the supplement with ginger extract at $20 \mathrm{mg} / \mathrm{kg}$ showed negligible effects on all phenotypic parameters, comparisons in gene expression were restricted to water control, fructose control and fructose ginger $50 \mathrm{mg} / \mathrm{kg}$ groups.

By real-time PCR, fructose feeding increased renal expression of mRNAs corresponding to monocyte chemotactic protein (MCP)-1 (Figure 6A), chemokine (C-C motif) receptor (CCR)-2 (Figure 6B), CD68 (Figure 6C),

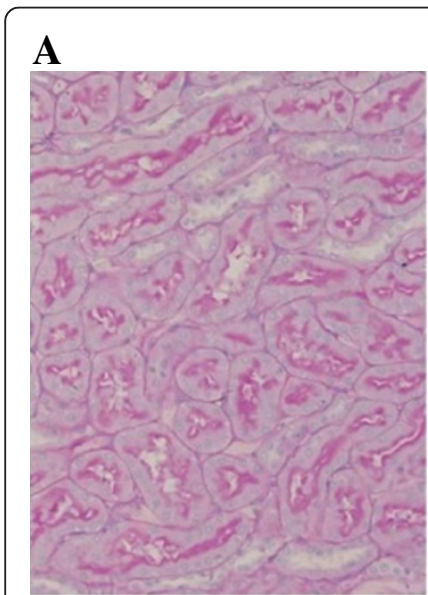

E Water control $\quad$ F

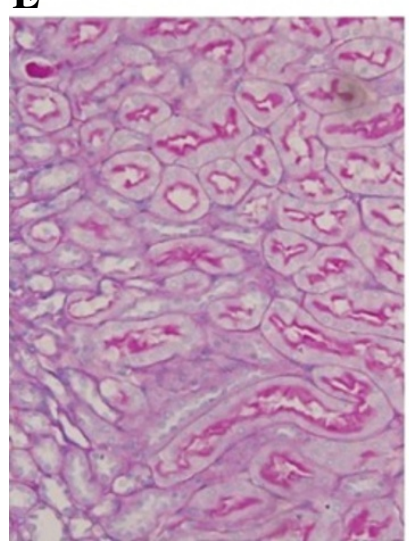

Water control

\section{B}

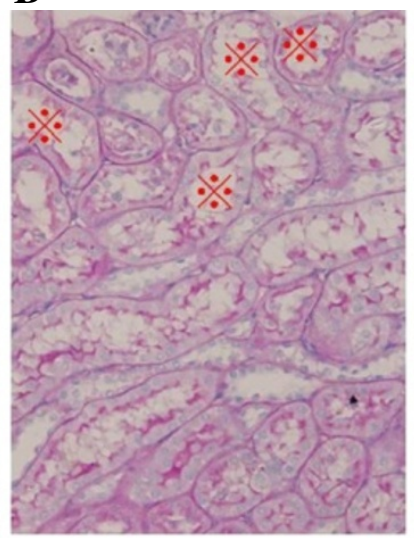

Fructose control F

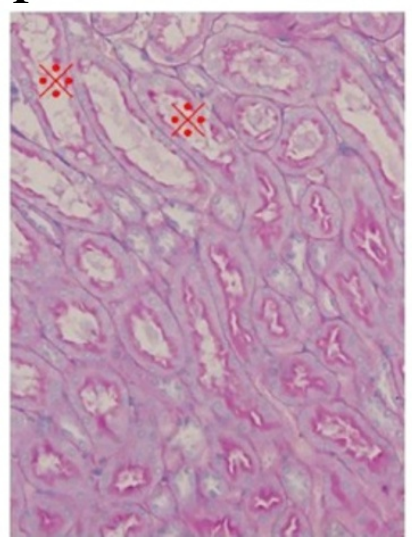

Fructose control
C

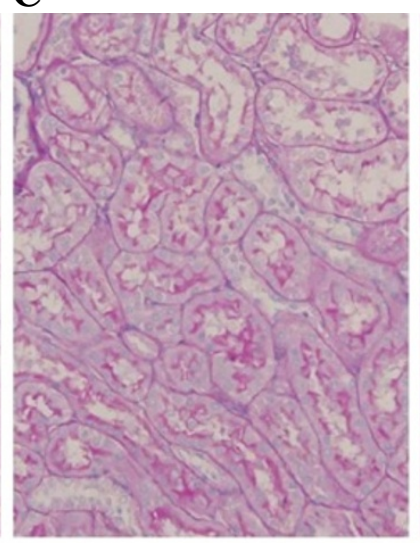

Fructose ginger 20

G

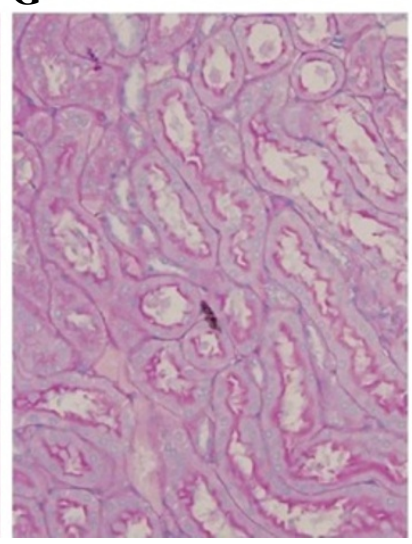

Fructose ginger 20
D

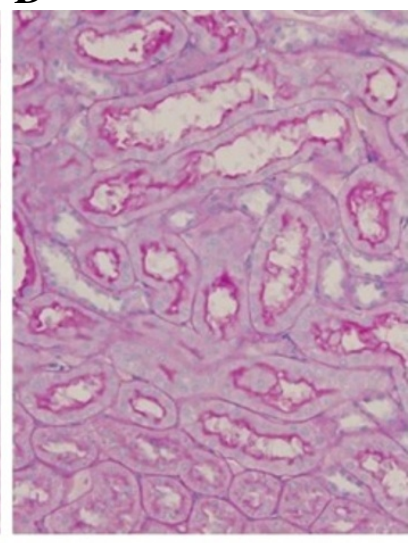

H

Fructose ginger 50

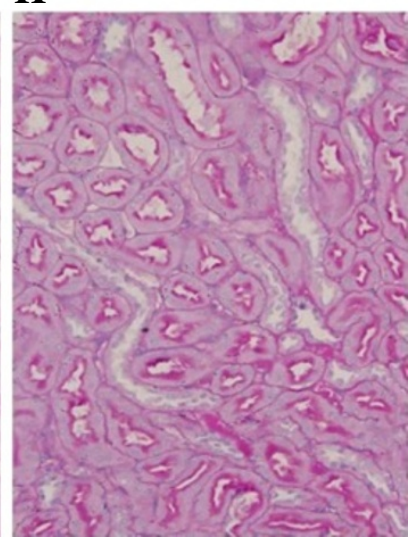

Fructose ginger 50

Figure 3 Representative images showing tubular damages characterized by focal cast formation, slough and dilation of tubular epithelial cells (with $※$, periodic acid-Schiff staining, magnification: $400 \mathrm{X}$ ) in the cortex of kidney in rats (A-H). The fructose control rats had free access to $10 \%$ fructose in their drinking water over 5 weeks, while the consumption of fructose in the ginger (20 or $50 \mathrm{mg} / \mathrm{kg})$-treated (by gavage daily) rats was adjusted to that of the fructose control rats. The water-control rats had free access to tap water. 


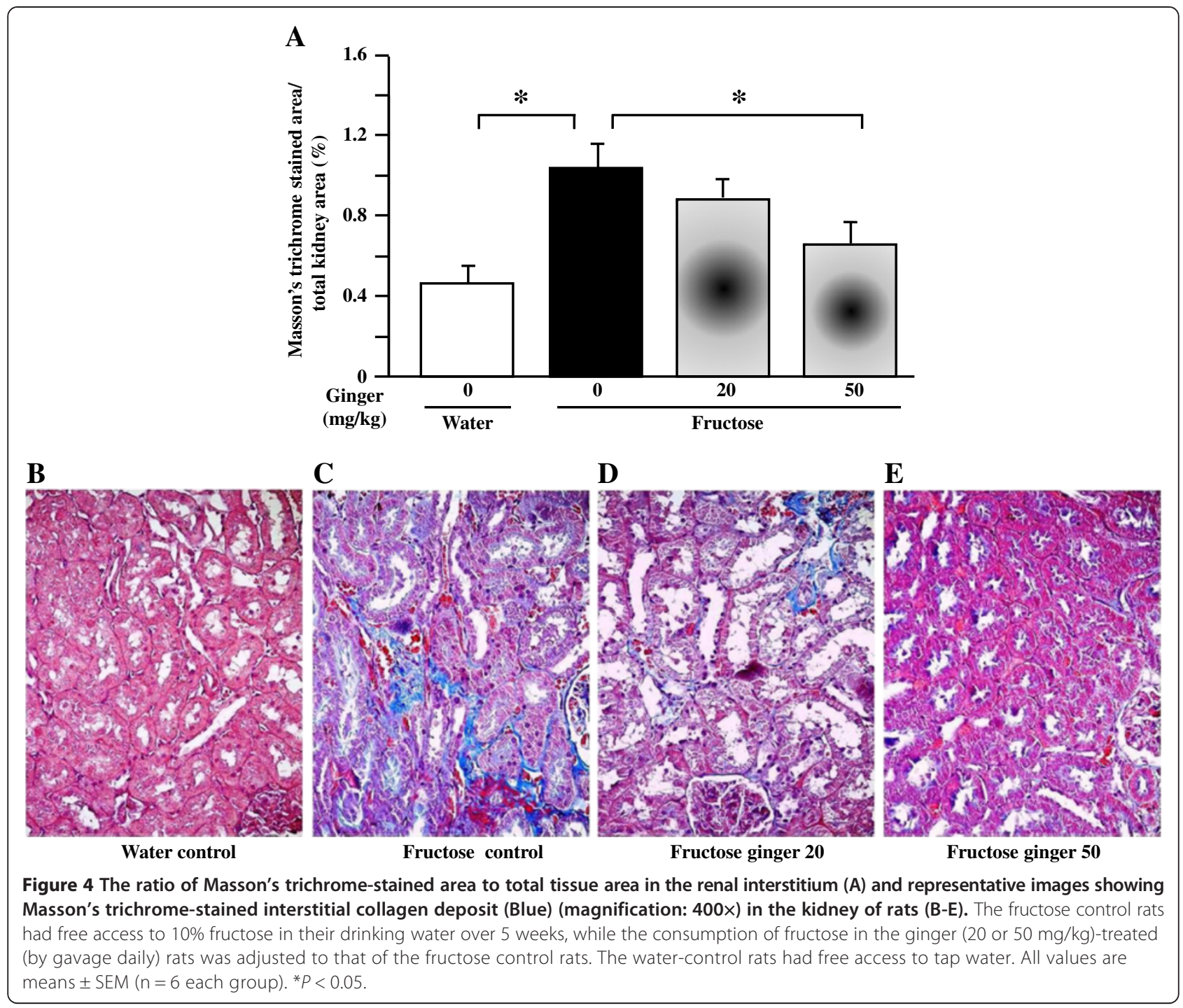

F4/80 (Figure 6D), TNF- $\alpha$ (Figure 7A), IL-6 (Figure 7B), transforming growth factor (TGF)- $\beta 1$ (Figure $7 \mathrm{C}$ ) and plasminogen activator inhibitor (PAI)-1 (Figure 7D). Although urokinase-type plasminogen activator (uPA) was not altered (Figure 7E), the ratio of UPA to PAI-1 expression was significantly downregulated by fructose feeding (Figure 7F). Ginger supplement substantially suppressed renal overexpression of MCP-1, CCR-2, CD68, F4/80, TNF- $\alpha$, IL-6, TGF- $\beta 1$ and PAI-1 (Figures 6A-D and Figures 7A-D), and restored the downregulated ratio of uPA to PAI-1 (Figure 7F).

\section{Discussion}

Ginger has been demonstrated to protect rats from ischemia/reperfusion- [18,19], alcohol- [20,21], streptozotocin[22] and carbon tetrachloride- [23] induced renal injuries. Recently, we have demonstrated that ginger supplement improves fructose consumption-induced fatty liver [24] and adipose tissue insulin resistance [25] in rats. The present study investigated the effects of ginger on chronic fructose consumption-associated kidney injury. Consistent with the previous findings [13], the present results demonstrate that five-week fructose consumption induced kidney remodeling as characterized by focal cast formation, slough and dilation of tubular epithelial cells in the cortex and outer stripe of the medullas, and excessive interstitial collagen deposit in rats. However, these pathological changes were accompanied by minimal alteration in glomerular structure and concentrations of BUN and plasma creatinine. It is possible that the mild initial histological changes do not induce pronounced alterations in renal functionality. Supplementing with a ginger extract $(50 \mathrm{mg} / \mathrm{kg}$ ) attenuated the proximal tubular damage and interstitial fibrosis in the kidneys and these effects were accompanied by improvements in hyperinsulinemia and hypertriglyceridemia. Therefore, 


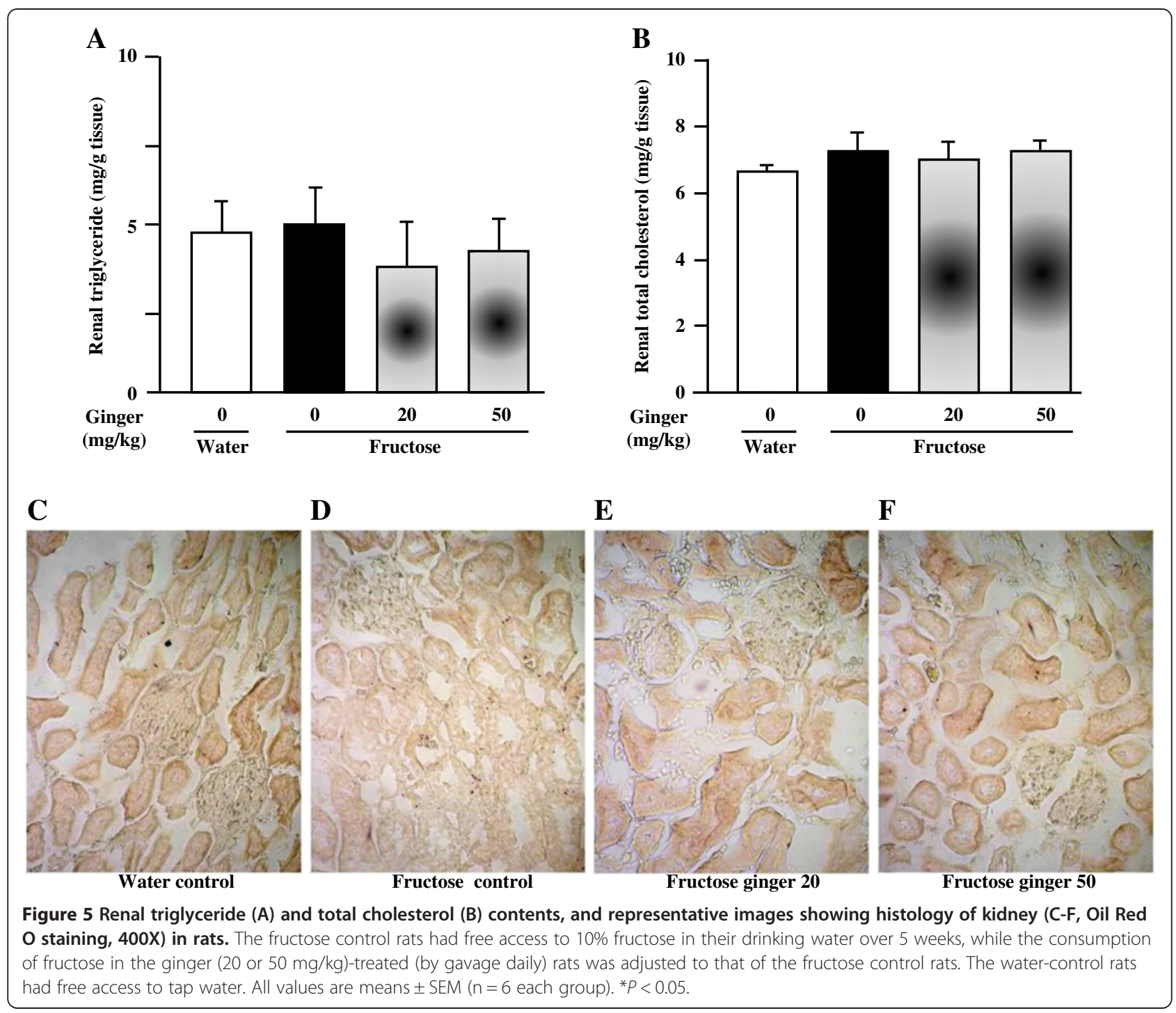

these results present evidence suggesting that ginger possesses protective effect against the initial stages of the metabolic syndrome-associated kidney injury.

Renal inflammation is known to play an important role in the initiation and progression of tubulointerstitial injury in the kidneys [32,33]. Fructose has been demonstrated to induce production of macrophageassociated MCP-1 in human kidney proximal tubular cells [34]. Fructose consumption leads to cortical tubular damage with inflammatory infiltrates [12]. MCP-1 promotes monocyte and macrophage migration and activation, and upregulates expression of adhesion molecules and other proinflammatory cytokines. Studies indicate that the local expression of MCP-1 at sites of renal injury promotes macrophage adhesion and chemotaxis through ligation of CCR-2 [35]. In patients, tubular MCP-1 is elevated in progressive renal diseases [36] and albuminuria is associated with MCP-1 and macrophage infiltration [37]. The infiltrated macrophages produce numerous proinflammatory cytokines, such as TNF- $\alpha$ [38], which has been shown to mediate inflammation in several models of renal injury, including tubulointerstitial injury [39]. It has been reported that gingerols, [6]-shogaol and 1-dehydro-[10]-gingerdione inhibit lipopolysaccharide-stimulated release and gene expression of proinflammatory cytokines including MCP-1 and IL-6 in RAW 264.7 macrophages and cultured primary rat astrocytes [40-43]. In addition, another component of ginger, known as zingerone, has also been shown to suppress the inflammatory action of macrophages and release of MCP-1 from adipocytes, thereby blunting the inflammatory response of adipose tissue in obesity [44]. These findings have been corroborated by a study we have recently conducted in rats demonstrating the modulatory effects of ginger on adipose expression of macrophagerelated proinflammatory cytokines thereby ameliorating fructose-induced adipose tissue insulin resistance [25]. 


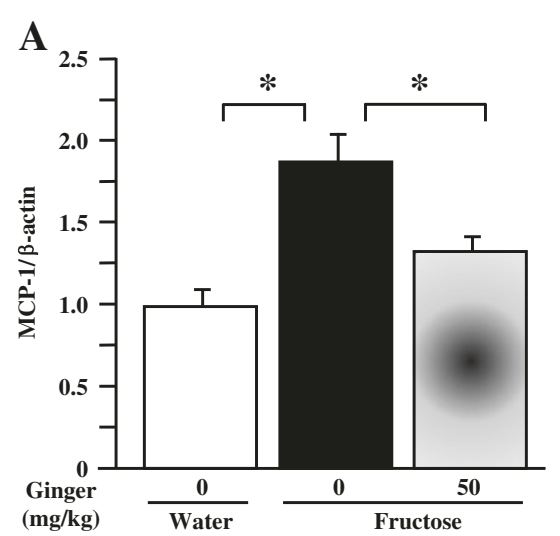

C

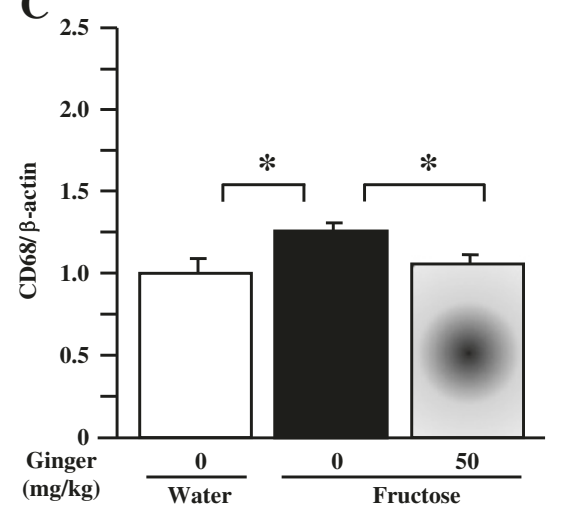

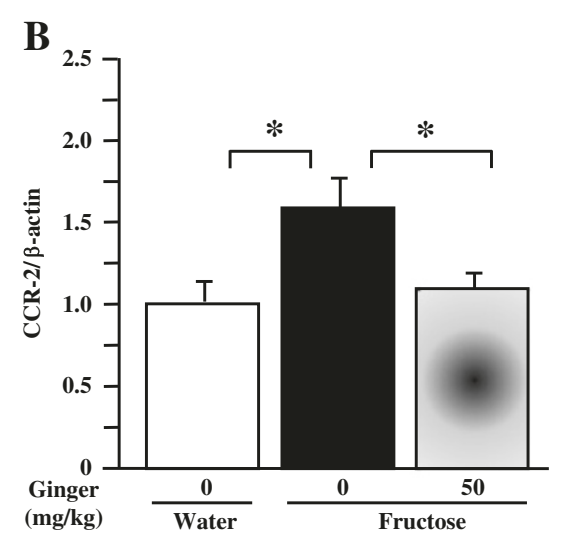

D

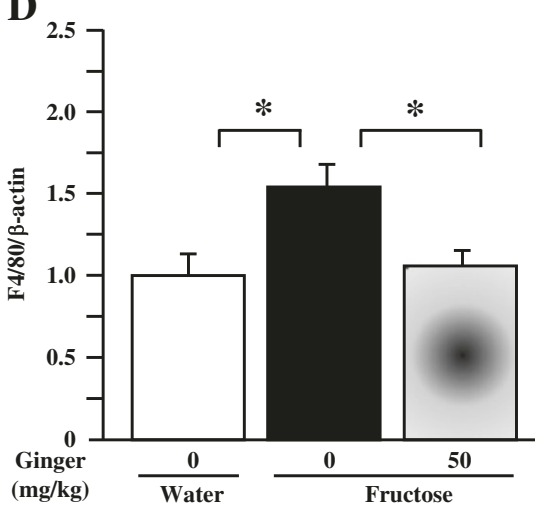

Figure 6 Renal mRNA expression of monocyte chemotactic protein (MCP)-1 (A), chemokine (C-C motif) receptor (CCR)-2 (B), CD68 (C) and F4/80 (D) in rats. The fructose control rats had free access to 10\% fructose in their drinking water over 5 weeks, while the consumption of fructose in the ginger (20 or $50 \mathrm{mg} / \mathrm{kg}$ )-treated (by gavage daily) rats was adjusted to that of the fructose control rats. The water-control rats had free access to tap water. mRNA was determined by Real-Time PCR. Levels in water-control rats were assigned a value of 1 . All values are means \pm SEM ( $n=6$ each group). ${ }^{*} P<0.05$.

The present study found that the ginger extract containing [6]-gingerol and [6]-shogaol was able to suppress fructose-induced overexpression of MCP-1, CCR-2, CD68 and F4/80 (two important macrophage markers $[45,46])$, TNF- $\alpha$ and IL- 6 in the kidneys. These findings are consistent with the attenuation of proximal tubular injury. Thus, the renoprotective effect of ginger supplement is associated with suppression of renal overexpression of macrophage-associated proinflammatory cytokines.

Proinflammatory cytokines are associated with renal fibrosis. It has been demonstrated that blockading MCP-1 and its receptor CCR-2 pathway reduces renal fibrosis [47]. The activated macrophages also produce other proinflammatory cytokines, such as IL- 6 , TGF- $\beta 1$ and PAI- 1 [38]. IL-6 was shown to enhance TGF- $\beta 1$ signaling via modulation of TGF- $\beta 1$ receptor trafficking, an effect that may enhance renal fibrosis [48]. TGF- $\beta 1$ may activate the plasmin system by stimulating gene expression of PAI-1, the principal inhibitor of plasminogen activation [49]. PAI-1 has a number of important roles in pathophysiological processes, such as inhibition of fibrinolysis, regulation of extracellular matrix turnover and activation of proenzymes and latent growth factors that promote tissue fibrosis and sclerosis [48]. In progressive renal diseases, PAI-1 has been identified as a critical mediator of glomerulosclerosis and interstitial fibrosis [50,51]. The altered uPA to PAI-1 ratio reflects a change from a profibrinolytic to an antifibrinolytic state [52]. The shift toward the uPA-enriched profibrinolytic state favors renal collagen degradation. Given its pathophysiological role, studies into TGF- $\beta 1$ have found that [6]-gingerol inhibits its stimulation of myofibroblast differentiation and collagen production in nasal polyp-derived fibroblasts [53] and of proteoglycan core protein synthesis in human vascular smooth muscle cells [54]. In the present study, fructoseinduced upregulation of MCP-1, CCR-2, IL-6, TGF- $\beta 1$ and PAI-1 gene expression in kidney was suppressed by ginger supplement $(50 \mathrm{mg} / \mathrm{kg})$. The ratio of uPA to PAI-1 was also restored. Thus, ginger-elicited diminishment of renal interstitial fibrosis is also associated with suppression of renal overexpression of proinflammatory cytokines, thereby improving profibrinolytic state.

Lipid accumulation in nonadipose tissues has been increasingly recognized to contribute to organ injury 

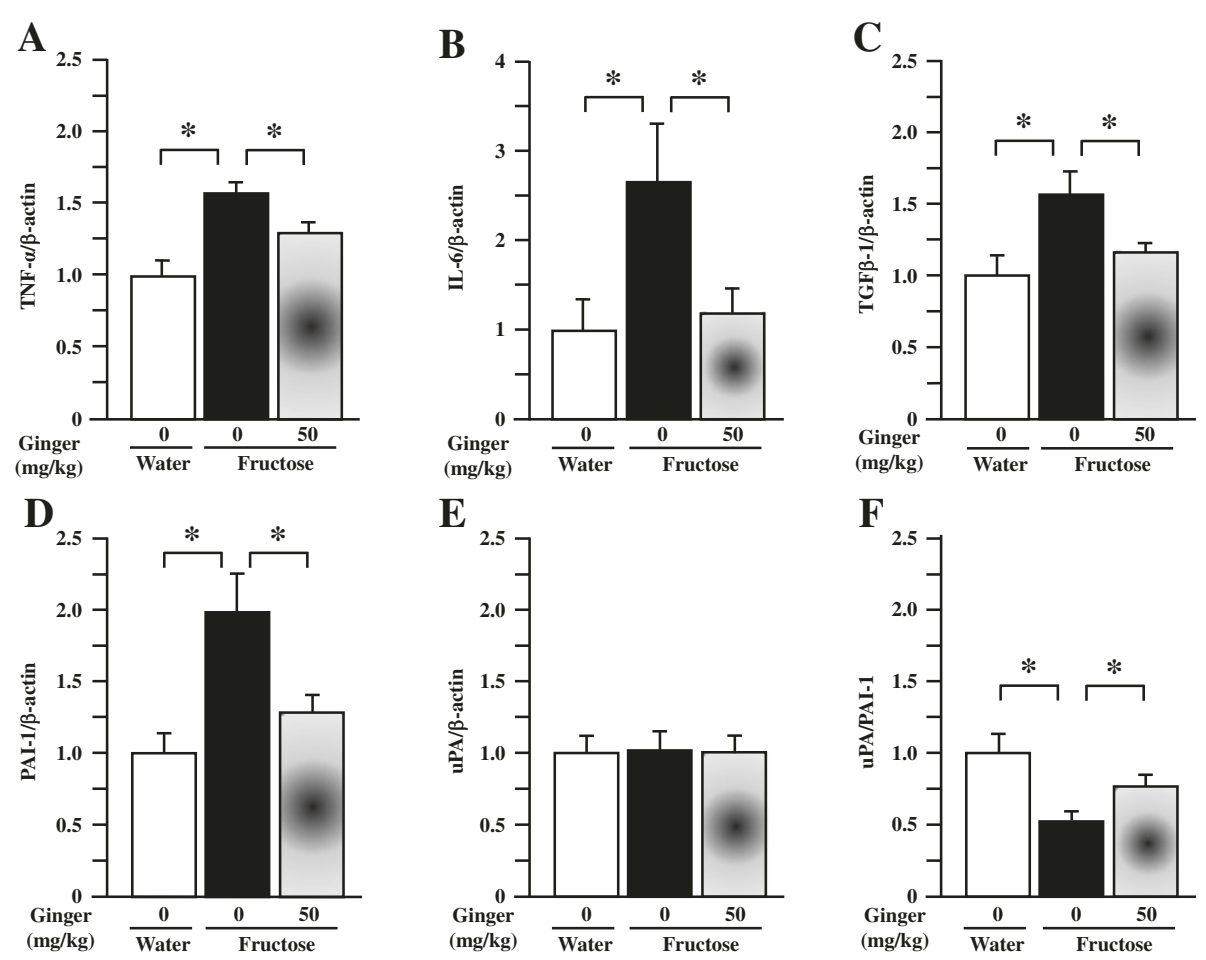

Figure 7 Renal mRNA expression of tissue necrosis factor (TNF)- $\alpha$ (A), interleukin (IL)-6 (B), transforming growth factor (TGF)- $\beta 1$ (C), plasminogen activator inhibitor (PAI)-1 (D), urokinase-type plasminogen activator (UPA) (E) and the ratio of uPA to PAI-1 (F) in rats. The fructose control rats had free access to $10 \%$ fructose in their drinking water over 5 weeks, while the consumption of fructose in the ginger ( 20 or $50 \mathrm{mg} / \mathrm{kg}$ )-treated (by gavage daily) rats was adjusted to that of the fructose control rats. The water-control rats had free access to tap water. mRNA was determined by Real-Time PCR. Levels in water-control rats were assigned a value of 1 . All values are means \pm SEM ( $n=6$ each group). ${ }^{*} P<0.05$.

through a process termed lipotoxicity. There is substantial evidence that excess renal lipids can cause injury in animal models of metabolic disease (obesity, metabolic syndrome and diabetes mellitus), chronic kidney disease, acute renal injury of several etiologies, as well as aging [55]. Lipotoxic cellular dysfunction and injury occur through several mechanisms such as release of proinflammatory and profibrotic factors [55]. Fructose consumption may induce excessive lipid accumulation in liver [27]. We have recently demonstrated that treatment with the ethanolic extract of ginger attenuates fructoseinduced fatty liver in rats [24]. In the present study, however, five-week fructose feeding did not alter renal accumulation of triglyceride and total cholesterol in rats. Ginger treatment (20 and $50 \mathrm{mg} / \mathrm{kg}$ ) also did not affect renal lipid contents in fructose-fed rats. Thus, it is unlikely that ginger treatment ameliorates fructose-induced renal injury in rats via modification of renal lipid metabolism.

While there are numerous constituents in ginger, the two prominent components [6]-gingerol and [6]-shogaol have been implicated in the majority of pharmacological activities associated with ginger [16]. At this point, further investigation is needed to broaden our collective knowledge regarding the details surrounding the therapeutic actions of ginger. Specifically, whether [6]-gingerol, [6]shogaol, or a combination thereof is responsible for the diminishment of fructose-induced renal injury, their specific function on macrophages, and the manner in which they suppress proinflammatory cytokines.

\section{Conclusion}

Our present results demonstrate that supplement with ginger extract at $50 \mathrm{mg} / \mathrm{kg}$ attenuates chronic fructose consumption-induced kidney injury in rats by suppressing renal overexpression of proinflammatory cytokines. Our findings provide evidence supporting the benefit of ginger supplement for the metabolic syndrome-associated kidney injury.

\section{Abbreviations}

BUN: Blood urea nitrogen; BW: Body weight; CCR: Chemokine (C-C motif) receptor; IL: Interleukin; MCP: Monocyte chemoattractant protein;

PAl: Plasminogen activator inhibitor; PAS: Periodic acid-schiff; TGF: Transforming growth factor; TNF: Tumor necrosis factor; UPA: Urokinase-type plasminogen activator.

\section{Competing interests}

The authors have declared that no conflict of interest exists. 


\section{Authors' contribution}

$\mathrm{CL}$ and MY performed the experiments, analyzed/interpreted data and drafted the manuscript. JJ, GZ, XL and JY analyzed/interpreted data. JW and $Y L$ contributed to the concept, designed experiments, analyzed/interpreted data and finalized the manuscript. All coauthors reviewed and discussed the paper. All authors read and approved the final manuscript.

\section{Acknowledgments}

We thank Mr. Alan Yeung for his excellent assistance in the preparation of this manuscript. This work was financially supported by National Natural Science Foundation of China (Grant 81374033), China, and R\&D Agency for Curative Natural Products (a Japanese government-registered non-profit organization), Kyoto, Japan.

\section{Author details}

${ }^{1}$ Faculty of Basic Medical Sciences, Chongqing Medical University, Chongqing 400016, China. ${ }^{2}$ College of Laboratory Medicine, Chongqing Medical University, Chongqing 400016, China. ${ }^{3}$ Endocrinology and Metabolism Group, Sydney Institute of Health Sciences/Sydney Institute of Traditional Chinese Medicine, Sydney, NSW 2000, Australia. ${ }^{4}$ Pharmafood Institute, Kyoto 602-8136, Japan. ${ }^{5}$ Department of Traditional Chinese Medicine, Chongqing Medical University, Chongqing 400016, China.

Received: 6 December 2013 Accepted: 20 May 2014

Published: 27 May 2014

\section{References}

1. Chen J, Muntner P, Hamm LL, Jones DW, Batuman V, Fonseca V, Whelton PK, He J: The metabolic syndrome and chronic kidney disease in US adults. Ann Intern Med 2004, 140:167-174.

2. Kurella M, Lo JC, Chertow GM: Metabolic syndrome and the risk for chronic kidney disease among nondiabetic adults. J Am Soc Nephrol 2005, $16: 2134-2140$

3. Li Y, Qi Y, Kim MS, Xu KZY, Huang THW, Rong X, Murray M, Yamahara J: Increased renal collagen cross-linking and lipid accumulation in nephropathy of Zucker diabetic fatty rats. Diabetes-metab Res Rev 2008, 24:498-506.

4. He L, Qi Y, Rong X, Jiang J, Yang Q, Yamahara J, Murray M, Li Y: The Ayurvedic medicine Salacia oblonga attenuates diabetic renal fibrosis in rats: suppression of angiotensin II/AT1 signaling. Evid-Based Complement Alternat Med 2011, 2011:807451.

5. Ziyadeh FN, Hoffman BB, Han DC, La Cruz MC I-D, Hong SW, Isono M, Chen S, McGowan TA, Sharma K: Long-term prevention of renal insufficiency, excess matrix gene expression, and glomerular mesangial matrix expansion by treatment with monoclonal anti-transforming growth factor-antibody in $\mathrm{db} / \mathrm{db}$ diabetic mice. Proc Natl Acad Sci USA 2000, 97:8015-8020.

6. Odermatt A: The Western-style diet: a major risk factor for impaired kidney function and chronic kidney disease. Am J Physiol Renal Physiol 2011, 301:F919-F931.

7. Elliott SS, Keim NL, Stern JS, Teff K, Havel PJ: Fructose, weight gain, and the insulin resistance syndrome. Am J Clin Nutr 2002, 76:911-922.

8. Jacobson MF: High-fructose corn syrup and the obesity epidemic. Am J Clin Nutr 2004, 80:1081-1082.

9. Jürgens H, Haass W, Castaneda TR, Schürmann A, Koebnick C, Dombrowski F, Otto B, Nawrocki AR, Scherer PE, Spranger J, Ristow M, Joost HJ, Havel PJ, Tschöp MH: Consuming fructose-sweetened beverages increases body adiposity in mice. Obes Res 2005, 13:1146-1156.

10. Nakagawa T, Tuttle KR, Short RA, Johnson RJ: Hypothesis: fructoseinduced hyperuricemia as a causal mechanism for the epidemic of the metabolic syndrome. Nat Clin Pract Nephrol 2005, 1:80-86.

11. Nakagawa T, Hu H, Zharikov S, Tuttle KR, Short RA, Glushakova O, Ouyang X, Feig DI, Block ER, Herrera-Acosta J, Johnson RJ: A causal role for uric acid in fructose-induced metabolic syndrome. Am J Physiol Renal Physiol 2006, 290:F625-F631.

12. Kizhner T, Werman MJ: Long-term fructose intake: biochemical consequences and altered renal histology in the male rat. Metabolism 2002, 51:1538-1547.

13. Nakayama T, Kosugi T, Gersch M, Connor T, Sanchez-Lozada LG, Lanaspa MA, Roncal C, Perez-Pozo SE, Johnson R, Nakagawa T: Dietary fructose causes tubulointerstitial injury in the normal rat kidney. Am J Physiol Renal Physiol 2010, 2010(298):F712-F720.
14. Oudot C, Lajoix AD, Jover B, Rugale C: Dietary sodium restriction prevents kidney damage in high fructose-fed rats. Kidney Int 2013, 83:674-683.

15. Aoyama M, Isshiki K, Kume S, Chin-Kanasaki M, Araki H, Araki SI, Koya D, Haneda M, Kashiwagi A, Maegawa H, Uzu T: Fructose induces tubulointerstitial injury in the kidney of mice. Biochem Biophys Res Commun 2012, 419:244-249.

16. Ali BH, Blunden G, Tanira MO, Nemmar A: Some phytochemical, pharmacological and toxicological properties of ginger (Zingiber officinale Roscoe): a review of recent research. Food Chem Toxicol 2008, 46:409-420

17. Nicoll R, Henein MY: Ginger (Zingiber officinale Roscoe): A hot remedy for cardiovascular disease? Int J Cardiol 2009, 131:408-409.

18. Uz E, Karatas OF, Mete E, Bayrak R, Bayrak O, Atmaca AF, Atis O, Yildirim ME, Akcay A: The effect of dietary ginger (Zingiber officinals Rosc) on renal ischemia/reperfusion injury in rat kidneys. Ren Fail 2009, 31:251-260.

19. Maghsoudi S, Gol A, Dabiri S, Javadi A: Preventive effect of ginger (Zingiber officinale) pretreatment on renal ischemia-reperfusion in rats. Eur Surg Res 2011, 46:45-51.

20. Shanmugam KR, Ramakrishna CH, Mallikarjuna K, Reddy KS: Protective effect of ginger against alcohol-induced renal damage and antioxidant enzymes in male albino rats. Indian J Exp Biol 2010, 48:143-149.

21. Ramudu SK, Korivi M, Kesireddy N, Chen CY, Kuo CH, Kesireddy S: Ginger feeding protects against renal oxidative damage caused by alcohol consumption in rats. J Ren Nutr 2011, 21:263-270.

22. Ramudu SK, Korivi M, Kesireddy N, Lee LC, Cheng IS, Kuo CH, Kesireddy SR: Nephro-protective effects of a ginger extract on cytosolic and mitochondrial enzymes against streptozotocin (STZ)-induced diabetic complications in rats. Chin J Physiol 2011, 54:79-86.

23. Hamed MA, Ali SA, El-Rigal NS: Therapeutic potential of ginger against renal injury induced by carbon tetrachloride in rats. ScientificWorldJournal 2012, 2012:840421.

24. Gao H, Guan T, Li C, Zuo G, Yamahara J, Wang J, Li Y: Treatment with ginger ameliorates fructose-induced fatty liver and hypertriglyceridemia in rats: modulation of the hepatic carbohydrate response element binding protein-mediated pathway. Evid-Based Complement Alternat Med 2012, 2012:570948.

25. Wang J, Gao H, Ke D, Zuo G, Yang Y, Yamahara J, Li Y: Improvement of liquid fructose-induced adipose tissue insulin resistance by ginger treatment in rats is associated with suppression of adipose macrophage-related pro-inflammatory cytokines. Evid-Based Complement Alternat Med 2013, 2013:590376.

26. Rong X, Peng G, Suzuki T, Yang Q, Yamahara J, Li Y: A 35-day gavage safety assessment of ginger in rats. Regul Toxicol Pharmacol 2009, 54:118-123.

27. Tappy L, Lê KA: Metabolic effects of fructose and the worldwide increase in obesity. Phys Rev 2010, 90:23-46.

28. Liu C, Li Y, Zuo G, Xu W, Gao H, Yang Y, Yamahara J, Wang J, Li Y: Oleanolic acid diminishes liquid fructose-induced fatty liver in rats: role of modulation of hepatic sterol regulatory element-binding protein 1c-mediated expression of genes responsible for de novo fatty acid synthesis. Evid-Based Complement Alternat Med 2013, 2013:534084.

29. Liu L, Yang M, Lin X, Li Y, Liu C, Yang Y, Yamahara J, Wang J, Li Y: Modulation of hepatic sterol regulatory element-binding protein-1cmediated gene expression contributes to Salacia oblonga root-elicited improvement of fructose-induced fatty liver in rats. J Ethnopharmacol 2013, 150:1045-1052.

30. Madkor HR, Mansour SW, Ramadan G: Modulatory effects of garlic, ginger, turmeric and their mixture on hyperglycaemia, dyslipidaemia and oxidative stress in streptozotocin-nicotinamide diabetic rats. Br J Nutr 2011, 105:1210-1217.

31. Al-Amin ZM, Thomson M, Al-Qattan KK, Peltonen-Shalaby R, Ali M: Anti-diabetic and hypolipidaemic properties of ginger (Zingiber officinale) in streptozotocin-induced diabetic rats. Br J Nutr 2006, 96:660-666.

32. Goor HV, Ding G, Kees-Folts D, Grond J, Schreiner GF, Diamond JR: Macrophages and renal disease. Lab Invest 1994, 71:456-464.

33. Eardley KS, Cockwell P: Macrophages and progressive tubulointerstitial disease. Kidney Int 2005, 68:437-455.

34. Cirillo P, Gersch MS, Mu W, Scherer PM, Kim KM, Gesualdo L, Henderson GN, Johnson RJ, Sautin YY: Ketohexokinase-dependent metabolism of fructose induces proinflammatory mediators in proximal tubular cells. J Am Soc Nephrol 2009, 20:545-553.

35. Furuichi K, Wada T, Iwata Y, Kitagawa K, Kobayashi K, Hashimoto H, Ishiwata Y, Asano M, Wang H, Matsushima K, Takeya M, Kuziel WA, Mukaida N, Yokoyama H: 
CCR2 signaling contributes to ischemia-reperfusion injury in kidney. J Am SoC Nephrol 2003, 14:2503-2515.

36. Grandaliano G, Gesualdo L, Ranieri E, Monno R, Montinaro V, Marra F, Schena FP: Monocyte chemotactic peptide-1 expression in acute and chronic human nephritides: a pathogenetic role in interstitial monocytes recruitment. J Am Soc Nephrol 1996, 7:906-913.

37. Eardley KS, Zehnder D, Quinkler M, Lepenies J, Bates RL, Savage CO, Howie AJ, Adu D, Cockwell P: The relationship between albuminuria, MCP-1/CCL2, and interstitial macrophages in chronic kidney disease. Kidney Int 2006, 69:1189-1197.

38. Galkina $E$, Ley $\mathrm{K}$ : Leukocyte recruitment and vascular injury in diabetic nephropathy. J Am Soc Nephrol 2006, 17:368-377.

39. Guo G, Morrissey J, McCracken R, Tolley T, Liapis H, Klahr S: Contributions of angiotensin II and tumor necrosis factor-alpha to the development of renal fibrosis. Am J Physiol Renal Physiol 2001, 280:F777-F785.

40. Tripathi S, Maier KG, Bruch D, Kittur DS: Effect of 6-gingerol on proinflammatory cytokine production and costimulatory molecule expression in murine peritoneal macrophages. J Surg Res 2007, 138:209-213.

41. Dugasani S, Pichika MR, Nadarajah VD, Balijepalli MK, Tandra S, Korlakunta JN: Comparative antioxidant and anti-inflammatory effects of [6]-gingerol, [8]-gingerol, [10]-gingerol and [6]-shogaol. J Ethnopharmacol 2010, 127:515-520.

42. Shim S, Kim S, Choi DS, Kwon YB, Kwon J: Anti-inflammatory effects of [6]-shogaol: potential roles of HDAC inhibition and HSP70 induction. Food Chem Toxicol 2011, 49:2734-2740.

43. Lee HY, Park SH, Lee M, Kim HJ, Ryu SY, Kim ND, Hwang BY, Hong JT, Han SB, Kim Y: 1-Dehydro-[10]-gingerdione from ginger inhibits IKK $\beta$ activity for $\mathrm{NF}-\mathrm{kB}$ activation and suppresses NF-kB-regulated expression of inflammatory genes. Br J Pharmacol 2012, 167:128-140.

44. Woo HM, Kang JH, Kawada T, Yoo H, Sung MK, Yu R: Active spice-derived components can inhibit inflammatory responses of adipose tissue in obesity by suppressing inflammatory actions of macrophages and release of monocyte chemoattractant protein-1 from adipocytes. Life Sci 2007, 80:926-931.

45. Di Gregorio GB, Yao-Borengasser A, Rasouli N, Varma V, Lu T, Miles LM, Ranganathan G, Peterson CA, McGehee RE, Kern PA: Expression of CD68 and macrophage chemoattractant protein-1 genes in human adipose and muscle tissues: association with cytokine expression, insulin resistance, and reduction by pioglitazone. Diabetes 2005, 54:2305-2313.

46. Galic S, Fullerton MD, Schertzer JD, Sikkema S, Marcinko K, Walkley CR, Izon D, Honeyman J, Chen ZP, Van Denderen BJ, Kemp BE, Steinberg GR: Hematopoietic AMPK $\beta 1$ reduces mouse adipose tissue macrophage inflammation and insulin resistance in obesity. J Clin Invest 2011, 121:4903-4915.

47. Kitagawa K, Wada T, Furuichi K, Hashimoto H, Ishiwata Y, Asano M, Takeya M, Kuziel WA, Matsushima K, Mukaida N, Yokoyama H: Blockade of CCR2 ameliorates progressive fibrosis in kidney. Am J Pathol 2004, 165:237-246.

48. Zhang $\mathrm{XL}$, Topley $\mathrm{N}$, Ito T, Phillips A: Interleukin- 6 regulation of transforming growth factor (TGF)-beta receptor compartmentalization and turnover enhances TGF-beta1 signaling. J Biol Chem 2005, 280:12239-12245.

49. Lund LR, Riccio A, Andreasen PA, Nielsen LS, Kristensen P, Laiho M, Saksela O, Blasi F, Danø K: Transforming growth factor-beta is a strong and fast acting positive regulator of the level of type-1 plasminogen-activator inhibitor messenger-RNA in Wi-38 human lung fibroblasts. EMBO J 1987, 6:1281-1286.

50. Eddy AA: Plasminogen activator inhibitor-1 and the kidney. Am J Physiol 2002, 283:F209-F220.

51. Fogo AB: Renal fibrosis: not just PAl-1 in the sky. J Clin Invest 2003, 112:326-328.

52. Deatrick KB, Eliason JL, Lynch EM, Moore AJ, Dewyer NA, Varma MR: Vein wall remodeling after deep vein thrombosis involves matrix metalloproteinases and late fibrosis in a mouse model. J Vasc Surg 2005, 42:140-148.

53. Park SA, Park $\mathrm{H}_{\text {, }}$ Cho JS, Moon YM, Lee SH, Kim TH, Lee SH, Lee HM: Effect of [6]-gingerol on myofibroblast differentiation in transforming growth factor beta 1-induced nasal polyp-derived fibroblasts. Am J Rhinol Allergy 2012, 26:97-103.
54. Kamato D, Babaahmadi Rezaei H, Getachew R, Thach L, Guidone D, Osman N, Roufogalis B, Duke CC, Tran VH, Zheng W, Little PJ: (S)-[6]-Gingerol inhibits TGF- $\beta$-stimulated biglycan synthesis but not glycosaminoglycan hyperelongation in human vascular smooth muscle cells. J Pharm Pharmacol 2013, 65:1026-1036.

55. Bobulescu IA: Renal lipid metabolism and lipotoxicity. Curr Opin Nephrol Hypertens 2010, 19:393-402.

doi:10.1186/1472-6882-14-174

Cite this article as: Yang et al.: Ginger extract diminishes chronic

fructose consumption-induced kidney injury through suppression of renal overexpression of proinflammatory cytokines in rats. BMC Complementary and Alternative Medicine 2014 14:174.

\section{Submit your next manuscript to BioMed Central and take full advantage of:}

- Convenient online submission

- Thorough peer review

- No space constraints or color figure charges

- Immediate publication on acceptance

- Inclusion in PubMed, CAS, Scopus and Google Scholar

- Research which is freely available for redistribution

Submit your manuscript at www.biomedcentral.com/submit
C Biomed Central 